Session 2451

\title{
Asking Students to Design their Own Laboratory Experiments
}

\author{
Joseph R.V. Flora \\ University of South Carolina - Columbia
}

\begin{abstract}
$\underline{\text { Abstract }}$
An undergraduate environmental engineering laboratory class was revised to include an open experiment in addition to traditional experiments. Each student group identified a problem, designed an experiment to address the problem, performed the experiment, and documented the results with a laboratory report. The topics selected were remediation of acid mine drainage, evaluating different absorbents for oil spills, evaluating water quality of campus buildings, and evaluating water quality in local rivers. An evaluative questionnaire was distributed to the students to assess the effectiveness of the open experiment compared to the traditional experiments in enhancing the student learning experience. A statistical analysis performed on the responses to several items on the questionnaire showed that students believed that the open experiment provided a better learning experience compared to traditional experiments. Student responses to open-ended questions revealed that most students enjoyed the experience of performing an open experiment and that it should be included as part of the laboratory class.

\section{$\underline{\text { Introduction }}$}

An ongoing movement to improve the science and engineering education experience has stimulated reforms in the approaches professors take to deliver education ${ }^{1-4}$. The renewed emphasis on enhancing student learning ${ }^{5,6}$ has resulted in various reforms ranging from the fundamental programmatic approach (e.g., revision of an entire program to include design at all levels ${ }^{7}$ and use of clinic classes at all levels ${ }^{8}$ ) to the more modest, typically single professor, approach (e.g., using multimedia programs ${ }^{9}$ and virtual instruments ${ }^{10}$ in laboratory courses).

This paper presents the author's experience in implementing open experiments in an undergraduate environmental engineering laboratory course. The rationale behind including open experiments in the course was to help students gain a better perspective in identifying and addressing open-ended problems. Such an approach has been used with varying degrees of success in environmental engineering ${ }^{8}$ and in other fields ${ }^{11-14}$. The purpose of this paper is to provide additional information that is directly relevant to and potentially useful for laboratory professors in environmental engineering. The class schedule, necessary preparations, difficulties encountered, and results of the end-of-semester evaluations are described.

Course Description

ECIV 350 (Introduction to Environmental Engineering) and ECIV 350L (Introduction to Environmental Engineering Laboratory) are junior-level undergraduate courses offered at the 
University of South Carolina - Columbia that are part of the requirements for the degree of Bachelor of Science in Civil Engineering. The prerequisite of ECIV 350 is General Chemistry and Calculus, while the co-requisite of ECIV 350L is ECIV 350. Both courses are taught once every school year during the Fall Semester. In addition to civil and environmental engineering majors, ECIV 350 draws students from other engineering and science disciplines. Students in ECIV 350L are primarily civil and environmental engineering majors.

ECIV 350L was historically taught in the traditional manner. Students were given handouts that described the theory behind the experiments and the procedures to follow in performing the experiments. Experiments were then performed as part of a group, and individually written documentation (i.e., laboratory reports or short memoranda) was submitted based on the results of each exercise. In Fall 1999, revisions were introduced to have a problem-based laboratory exercise that had more field orientation. In addition to traditional experiments, student groups were required to perform one open experiment. For the open experiment, each group identified a problem, designed an experiment to address the problem, performed the experiment, and documented the results with a laboratory report.

\section{Approach to Open Experiment and Selected Topics}

A total of 32 students were enrolled in two laboratory sections. Students were divided into groups for 4 for most laboratory exercises. For the open experiment, students were divided into groups of $7,8,8$, and 9 , resulting in 4 different experiments.

The course calendar distributed to students at the beginning of the semester was revised because class was disrupted by a hurricane and make-up classes were not scheduled by the university. Table 1 shows the effective course calendar that resulted with the interruptions.

Table 1. ECIV 350L Schedule for the Fall 1999 Semester.

\begin{tabular}{|c|l|l|}
\hline Week \# & \multicolumn{1}{|c|}{ Topics } & \multicolumn{1}{|c|}{ Open Experiment Schedule } \\
\hline 1 & Safety Seminar, Class Policies & \\
\hline 2 & Lab 1 - Adsorption & Deadline for Topic Selection \\
\hline 3 & Lab 1 (continued) - Adsorption & \\
\hline 4 & Hurricane (no class) & Formulate Procedures \\
\hline 5 & Lab 2 - pH \& Alkalinity & Submission of Proposal for Open Experiment \\
\hline 6 & Field Trip to Water Treatment Plant & Begin Purchase of Required Materials \\
\hline 7 & Lab 3 - Flocculation & Scheduling of Open Experiment \\
\hline 8 & Lab 4 - Oxidation & \\
\hline 9 & Lab 5 - BOD/COD \\
\hline 10 & Field Trip to Landfill Lab 6 (continued) - Open Experiments \\
\hline 11 & \multicolumn{2}{|c|}{ Lab 6 (continued) - Open Experiments } \\
\hline 12 & \multicolumn{2}{|c|}{} \\
\hline 13 & \multicolumn{2}{|c|}{} \\
\hline 14 & Wrap up and Evaluations & \\
\hline
\end{tabular}


Extensive discussions were held with each group during the first three weeks to ensure that the topic for the open experiment could be performed given the analytical capabilities and available resources in the Department. Each group brainstormed about current local environmental issues and frequently conferred with the instructional staff about the feasibility of performing an experiment on that topic. Students were encouraged to browse the literature and the Internet for information. Students were also reminded that they had to define a particular problem, keeping in mind that they should have an idea of the tests to be performed and the type of answers to expect from the tests.

Once each group's topic was finalized, procedures for the experiment were formulated following a process similar to the topic selection. Students brainstormed, browsed the literature, and consulted with the instructional staff. By the seventh week, students submitted a 1-2-page memo detailing the problem statement, proposed procedures, materials required, expected results, and expected conclusions. Additional required materials were purchased and a reservation for a van for field sampling was secured three weeks before the experiments. The experiments were scheduled to allow the instructional staff to cover 4 different experiments within the allotted time.

The following paragraphs provide a brief description of the open experiments performed and the logistics associated with each experiment.

Open Experiment 1 - Remediation of acid mine drainage. Students selected this topic based on recent news regarding the closure of a local mine. Based on the literature on the local mine and similar mines, students made a solution to simulate acid mine drainage. They evaluated the removal of a heavy metal from solution by precipitation through $\mathrm{pH}$ adjustment. The experiment was completed in 2 sessions during weeks 11 and 12 (see Table 1), and all the materials required were available in the laboratory.

Open Experiment 2 - Absorbents for oil spills. This topic was selected based on local and general news (e.g., the Exxon incident). Students evaluated the kinetics and capacity of various materials for absorbing oil. Each absorbent was weighed after soaking in oil for a period of time. Vegetable cooking oil was used instead of motor oil for ease of disposal. Syringes, tubing, cooking oil, and the different absorbents (human hair, kitty litter and Speedy-Dry (both clay products) and commercial oil absorbent padding) were obtained or purchased. The experiment was completed in 5 sessions during weeks 11 to 13 (see Table 1).

Open Experiment 3 - Water quality of campus buildings. The group selected this topic based on anecdotes about badly colored water in the dormitories. Students took first draw samples and measured the $\mathrm{pH}$, lead, and copper concentrations from seven campus buildings and the effluent from the local water treatment plant. Chemicals were purchased to allow for lead and copper quantification using spectrophotometric methods. The experiment was completed in 3 sessions during weeks 11 and 12 (see Table 1).

Open Experiment 4 - Water quality in local rivers. The group selected this topic because several students wanted to do an outdoor activity. Samples were withdrawn from six sampling points along three major local rivers and analyzed for dissolved oxygen (DO), chemical oxygen 
demand, and 5-day biochemical oxygen demand. A field DO meter was purchased and a device fabricated out of a 1-L plastic bottle, rope, and a brick was used to withdraw samples. A van was rented to accommodate the group and the instructor. The experiment was completed in 2 sessions during weeks 11 and 12 (see Table 1).

\section{Comparison of Open Experiment to Traditional Experiments}

An evaluative questionnaire was developed in conjunction with the college assessment office to evaluate the effectiveness of the open experiment compared to the traditional experiments in enhancing the student learning experience. The evaluation was in addition to the regular course and instructor evaluation administered by the college. A total of 30 students provided feedback.

The results of the questionnaire showed that only $17 \%$ of the student respondents had previous exposure to performing experiments that had an open structure, indicating that this was the first time most students were challenged to design their own experiment. $97 \%$ of the student respondents suggested that at least one open experiment be performed in ECIV 350L (the mean of the responses was 1.4), indicating that the practice of asking students to perform at least one open experiment should be continued.

Table 2 shows the composite student response to various items pertaining to learning, workload, and group dynamics. Statistical t-tests on the student responses showed that the open experiment enhanced learning compared to traditional experiments. Furthermore, it appeared that the total credit assigned to the open experiment justified the workload, and the groups worked very well when performing the open experiment.

Table 2. Composite Student Response to Various Items on the Questionnaire.

\begin{tabular}{|l|c|c|}
\hline \multicolumn{1}{|c|}{ Items } & Mean Response ${ }^{1}$ & $\begin{array}{c}95 \% \text { Confidence }^{\prime} \\
\text { Interval }^{1}\end{array}$ \\
\hline $\begin{array}{l}\text { 1. Compared to the traditional experiments, the open } \\
\text { experiment helped me better understand basic } \\
\text { environmental concepts. }\end{array}$ & 1.07 & $0.73-1.41$ \\
\hline $\begin{array}{l}\text { 2. Compared to the traditional experiments, the open } \\
\text { experiment helped me better visualize the application } \\
\text { aspects of theories learned in class. }\end{array}$ & 0.83 & $0.43-1.24$ \\
\hline $\begin{array}{l}\text { 3. Compared to the traditional experiments, the open } \\
\text { experiment helped me better understand how to design and } \\
\text { conduct experiments. }\end{array}$ & 1.27 & $0.86-1.67$ \\
\hline $\begin{array}{l}\text { 4. The total credit assigned to the open experiment (35\% for } \\
\text { report and memo) does not justify the workload. }\end{array}$ & 0.00 & $-0.37-0.37$ \\
\hline $\begin{array}{l}\text { 5. My group worked together very well when we performed } \\
\text { the open experiment. }\end{array}$ & 1.33 & $0.99-1.68$ \\
\hline
\end{tabular}

A one-factor analysis of variance $(\mathrm{ANOVA})^{15}$ was performed to evaluate if gender, student standing (junior vs. senior), or grade point average (GPA) affected the response to items in Table 2. All effects were evaluated at a significance level of $p=0.05$. The only significant difference involved student standing and the ability to visualize the application aspects of theories learned in class (see item 2, Table 2). Seniors had a significantly higher response than the juniors 
$\left(\operatorname{mean}_{\text {seniors }}=1.67 \mathrm{vs}\right.$. mean $\left._{\text {juniors }}=0.61\right)$. Although this is the first environmental engineering class and laboratory students took in the Department, it is possible that the seniors' exposure to laboratory classes in other areas and design-oriented classes gave them more maturity in visualizing application aspects with the open experiment.

The questionnaire also contained multiple open-ended questions to give students the opportunity to address the positive and negative aspects of the open experiment. Table 3 shows the questions asked, the major comments provided, and the percentage of students that provided the comment (shown in parenthesis before the comments). The percentage of students who did not provide any response to the question is also included. Several students gave multiple comments to each question.

Table 3. Open-ended Questions and Major Student Comments.

1. What did you like most about the experience of performing open experiments?

$(40 \%)$ Freedom to design experiment / freedom to generate own procedures.

$(30 \%)$ Freedom to select the experimental topic.

$(13 \%)$ Opportunity to do a field experiment to obtain data from actual samples.

$(0 \%)$ No response.

2. What did you like least about the experience of performing open experiments?

(27\%) Large groups.

(20\%) There was nothing I disliked.

$(10 \%)$ Topic selection.

$(0 \%)$ No response.

3. What suggestions would you give to enhance / improve the experience of performing open experiments?

(23\%) Smaller groups.

(20\%) Provide a list of potential open experiment topics.

(17\%) Everything is okay the way it is.

(3\%) No response.

4. What other topic(s) would you have wanted to work on as an open experiment?

(17\%) Various experiments focusing on rivers.

(13\%) Experiments involving air quality monitoring / control.

(10\%) Experiments involving soils.

(37\%) None / No suggestions / Not sure what to suggest / No response.

5. Other comments/suggestions/complaints?

$(23 \%)$ I enjoyed the experience of performing an open experiment.

$(10 \%)$ The fraction of the grade assigned to the open experiment was too much.

$(60 \%)$ No response.

The feedback shown in Table 3 indicates that the students generally enjoyed the experience of performing an open experiment. About $27 \%$ of the student respondents expressed their desire to have worked in smaller groups, although only $3 \%$ of the student respondents provided negative feedback regarding their group working well (from item 5 in Table 2). It is possible that although the group worked very well, students perceive that working in smaller groups would have provide a better laboratory experience. $20 \%$ of the student respondents suggested that a list of open experiment topics be provided to streamline the process of topic selection. $10 \%$ of the students voiced their concerns that too much weight was assigned to the open experiment in determining their final grade. 


\section{$\underline{\text { Conclusions }}$}

Although most students have not been exposed to the concept of performing an open experiment, students generally enjoyed the experience. Most students believed that the open experiment is better at enhancing learning compared to the traditional experiments, and that at least one open experiment should be included as part of future ECIV 350L classes. To improve on that experience, smaller student groups should be used and more initial guidance on topic selection should be provided.

The use of smaller student groups would result in a greater number of open experiments. The actual number and scope of the open experiments that can be performed will be limited by physical resource availability (e.g., instrumentation) and personnel limitations. Because this exercise is an academic activity, it is imperative that at least one instructional staff accompany students when gathering field samples in areas that may pose a hazard (e.g., sampling from a river). The primary instructional staff in ECIV 350L has traditionally been 1 professor and 1 teaching assistant, which limits the number of groups that can perform field sampling during each session. Time management would also be a challenge since the nature of the open experiments dictates that some sessions must be performed outside the scheduled class hours.

\section{Acknowledgements}

The author would like to thank the following people for providing valuable feedback and advice: Susan Creighton of the College Evaluation Office, Dr. Steve McAnally and Dr. Adrienne Cooper of the Department of Civil and Environmental Engineering, and Dr. Jed Lyons of the Department of Mechanical Engineering. This effort was supported in part by the National Science Foundation (BES 97-33377). Any opinions, findings, and conclusions or recommendations expressed in this material are those of the author and do not necessarily reflect the views of the funding agency. Mention of any specific trade name does not constitute endorsement of the product by the sponsors.

\section{$\underline{\text { References }}$}

1. Report of the Committee on Evaluation of Engineering Education, Journal of Engineering Education, 83(1), 74-94, 1994.

2. ASCE Summary Report: 1995 Civil Engineering Education Conference, American Society of Civil Engineers, New York, NY, 1995.

3. Hertz, D.W. Collaborative Development of New Design Tools to Improve Productivity, Innovation, and Learning, Environmental Engineering Education - The Relationship to Engineering Practice, Association of Environmental Engineering Professors Publication, Orono, ME, pp. 15-18, 1996

4. Denton, D.D. Engineering Education for the $21^{\text {st }}$ Century, Journal of Engineering Education, 88(1), 19-22, 1998.

5. Simon, H. What We Know About Learning, Journal of Engineering Education, 87(4), 343-348, 1998.

6. Campbell, M.E., Oh, Now I Get It! Journal of Engineering Education, 88(4), 381-383, 1999.

7. URL: http://www.soonercity.ou.edu/right, Sooner City Home Page, accessed 11/19/1999

8. Jahan, K. and Everett, J.W. An Innovative Environmental Design Module, Proceedings of the 1999 ASEE Annual Conference and Exposition, Charlotte, NC, June 20-23, 1999. 
9. Katz, L.E., Weathers, L.J., Kozlowski, R., Scott, M., and Manion, W., A Multimedia Based Laboratory Course for Environmental Engineering, Proceedings of the 1998 ASEE Annual Conference and Exposition, Seattle, WA, June 21-24, 1998.

10. Weber-Shirk, M.L. and Lion, L.W., Virtual Instruments in an Undergraduate Environmental Engineering Laboratory, Proceedings of the 1996 ASEE Annual Conference and Exposition, Washington, DC, June 23-26, 1996.

11. Middleburg, A. Laboratory Projects: Should Students Do Them or Design Them? Chemical Engineering Education, 29(1) 34-38, 1995.

12. Jayakumar, S., Squires, R.G., Reklaitis, G.V., Andersen, P.K., and Dietrich, B.K. The Purdue-Dow StyreneButadiene Polymerization Simulation, Journal of Engineering Education, 84(3), 271-278, 1995.

13. Arce, J. and Belancourt, R. Student-Designed Experiments in Scientific Lab Instruction, Journal of College Science Teaching, 27, 114-118, 1997.

14. Lyons, J.S., Morehouse, J.H., and Young, E. Design of a Laboratory to Teach Design of Experiments, Proceedings of the 1999 ASEE Annual Conference and Exposition, Charlotte, NC, June 20-23, 1999.

15. Neter, J., Wasserman, W., and Kutner, M.H. Applied Linear Statistical Models, Richard D. Irwin, Inc., Burr Ridge, IL, 1990.

\section{Biographical Information}

JOSEPH R.V. FLORA is an Associate Professor in the Department of Civil and Environmental Engineering at the University of South Carolina - Columbia. He received a B.S. in Civil Engineering from the University of the Philippines, a M.S. in Environmental Engineering from the University of Illinois at Urbana-Champaign and a Ph.D. in Environmental Engineering from the University of Cincinnati in 1993. He joined USC - Columbia in 1993. His research interests are in the areas of environmental process modeling, electrochemically-mediated biological degradation, and water, wastewater, and hazardous waste treatment. He is a licensed professional engineer in the State of South Carolina. 